\title{
Are complication rates lower with 4-Fr versus 6-Fr transfemoral arterial access - prospective audit at a single interventional radiology centre
}

\author{
Raymond Chung ${ }^{1 *}$, Alex Weller ${ }^{2}$, Robert Morgan ${ }^{3}$, Anna-Maria Belli ${ }^{3}$ and Lakshmi Ratnam ${ }^{3}$
}

\begin{abstract}
Background: Femoral arterial access constitutes the first step in a significant proportion of interventional endovascular procedures. Whilst existing reports describe sheath size as an independent risk factor for bleeding complications in radial arterial access for coronary intervention, the influence of sheath size on overall complication rates and morbidity following femoral arterial access is not well described. This prospective single centre study reports our experience of vascular sheath size, patient and procedural factors in influencing complication rates following femoral arterial access. From April 2010 to May 2013, data was collected prospectively for all femoral arterial access procedures performed in the Interventional Radiology department of a tertiary hospital. For vascular sheath size <6-Fr, haemostasis was achieved by manual compression. For 6-Fr sheath size, a closure device was used in the absence of any contraindication.

Results: Of the 320 femoral access cases with eligible inclusion criteria, 52.5\% had 4-Fr whilst $47.5 \%$ had 6-Fr vascular sheaths inserted. Overall post procedure complications rates were significantly higher following 6-Fr sheath $(17 / 152(11.2 \%))$ versus $4-F r$ systems (3/168 (1.8\%)) $(p=0.0007)$ mostly comprising self-limiting hematoma. There was no significant difference in major complications that required escalation of treatment.

Conclusion: No significant difference has been demonstrated between the use of either sheath systems for major complications. The practical limitations of a smaller system, combined with existing body of evidence, may not justify the routine use of 4-Fr sheath systems as the primary sheath size for all endovascular procedures.
\end{abstract}

Keywords: Access site related complications, Sheath size, Femoral arterial access

\section{Background}

Femoral arterial access constitutes the first step in a significant proportion of interventional endovascular procedures. Adequate training in safe arterial puncture (Fairley et al., 2016) and audit of outcomes are essential in minimising and recognising associated complications (Wagner et al., 2015; Rajebi \& Rajebi, 2015). Complications predominantly relate to haemorrhage following arterial access. Existing reports describe sheath size as an independent risk factor for increased bleeding

\footnotetext{
* Correspondence: rchung@doctors.org.uk

'Diagnostic Radiology, Khoo Teck Puat Hospital, 90, Yishun Central 768828,

Singapore

Full list of author information is available at the end of the article
}

complications in radial arterial access for coronary intervention (Honda et al., 2012). Femoral bleeding complications have been shown to change with sheath size, duration of femoral arterial access, as well as intensity and duration of anticoagulation (Doyle et al., 2008; Cantor et al., 2007). However, the influence of sheath size on overall complication rates and morbidity following femoral arterial access is not well described and is of particular interest given the potential mitigation of these complications with arterial closure devices (Tzinieris et al., 2007; Das et al., 2011; Baumann et al., 2015).

There has been an increase in the range of equipment available, which are compatible with 4-French (Fr) sheaths, including angioplasty balloons and $0.018^{\prime \prime}$ and $0.014 "$ 
systems. However, these are more expensive than their 6-Fr counterparts and the cost implications of using a smaller device and compatible systems is a consideration. Additionally, some technical limitations are associated with the use of the smaller systems. Patient and procedure related parameters also have an influence on complication rates. This study presents data from three audit cycles, conducted over three consecutive years, at a UK vascular IR (Interventional Radiology) centre. The aim was to assess the overall complication rates when using 4-French vascular access sheaths for femoral arterial endovascular interventions compared with 6-French sheaths; and evaluate the influence of patient and procedural parameters on these complication rates.

\section{Methods}

A prospective single centre study was conducted at a tertiary teaching hospital IR unit, over three 6 month audit cycles and includes all vascular interventions performed via the transfemoral route in the interventional radiology suites between April 2010 and May 2013.

All transfemoral arterial access was performed using sterile technique and $1 \%$ lidocaine infiltration at the puncture site. Fluoroscopic and/or ultrasound anatomical landmarks over the femoral head/neck were used to ensure safe site of arterial access in the common femoral arterial (CFA) segment. The CFA was also located by ultrasound with reference to the inferior epigastric artery origin. In our institution, all inexperienced operators receive formal training in the basics of safe femoral arterial puncture, followed by close senior supervision, until they are competent in gaining safe femoral arterial access. Competence is assessed on the basis of 50 observed retrograde and 50 observed antegrade punctures. Wherever possible, sheaths were removed immediately post procedure in the interventional suite and 10 min of manual compression was applied for haemostasis. Following the use of a 6-Fr vascular access sheath, a closure device is deployed in the absence of any contraindications.

\section{Patient demographics}

During the period of study, 392 arterial access procedures were performed, with 10 patients having two access sites. Fifty-eight cases were excluded as femoral sheath size was neither 4 Fr. nor 6 Fr. Additionally, nine 4-Fr and five 6-Fr cases were excluded as these were for alternative (non-femoral) access sites. In the remaining 320 procedures, 7 patients had bilateral femoral vascular access (4 patients having bilateral 4-Fr access, 2 patients having bilateral 6-Fr access, and 1 patient having one 4-Fr and one 6-Fr access). Patient clinical characteristics in the respective 4- $\mathrm{Fr}$ and 6 - $\mathrm{Fr}$ subpopulation are presented in Table 1 ( 1 patient with bilateral access with 4 and 6-Fr systems was included in each demographic as an individual entity). Of the 314 patients, 186 were male and 128 were female. Mean age was 65.7 (range 21-94) years (unavailable in 10 patients). $41.2 \%$ had hypertension whilst $31.0 \%$ had diabetes. $45.3 \%$ were receiving anticoagulation prior to the procedure, consisting of 4 patients on warfarin, 43 on aspirin, 8 on clopidogrel, 7 on treatment dose low molecular weight heparin, 42 on prophylactic dose low molecular weight heparin, and 36 patients on $>1$ of the aforementioned anticoagulation regimes. $2.3 \%$ had an INR $>1.5$.

Procedure related complications were recorded for all patients operated on during the audit periods, with clinical data collated on an audit pro-forma, both immediately following each procedure and prior to discharge from hospital. Parameters relating to both the patient and the procedure were recorded, including: patient co-morbidities; body habitus; vessel calcification; haematological clotting status; concomitant anti-coagulation; operator experience; sheath size and the number of needle passes attempted to gain successful arterial access. The association of these factors, especially sheath size, with post-procedural complications was evaluated.

Complications were classified based on the Society of Interventional Radiology (SIR) guidelines. Minor complications are defined as those requiring no treatment. Major complications are those requiring treatment and further hospitalization, those requiring an unplanned increase in level of care, those with permanent adverse sequelae, and those resulting in death (Omary et al., 2003).

\section{Statistical analysis}

Categorical variables were compared using Chi-squared analysis or Fisher's exact test (SPSS software) and were adjusted for confounding factors. Statistical significance was defined as $P<0.05$ ).

\section{Results \\ Arterial access site characteristics}

The arterial access site characteristics, operator seniority and methods of closure are recorded in Table 2. 75.6\% were retrograde access, with the majority $(95.3 \%)$ constituting puncture of the common femoral artery. 85\% were successful with a single anterior wall puncture. 4-Fr vascular access sheaths were used in $52.5 \%$, whilst 6 -Fr sheaths were used in $47.5 \%$. The vessels were calcified in $35.9 \%$ and the groins were scarred due to a previous surgical intervention in $16.6 \%$.

Arterial puncture was achieved with either ultrasound guidance alone (44.7\%) or a combination of ultrasound and fluoroscopic guidance (34.4\%); only $15.9 \%$ were accessed by manual palpation alone. $78.1 \%$ of access sites were sealed by manual compression. Punctures performed under manual palpation alone showed no significant difference in complication rates $(1 / 51$ patients $=2.0 \%)$ compared 
Table 1 Patient demographics

\begin{tabular}{|c|c|c|}
\hline & 4-Fr vascular sheath size population & 6-Fr vascular sheath size population \\
\hline No. of procedures & 168 & 152 \\
\hline No. of patients & 164 & 150 \\
\hline Age - mean (range) years & $61.7(21-92)$ & $69.7(21-94)$ \\
\hline Sex M:F & 71:93 & 115:35 \\
\hline Hypertension & $52(32.7 \%)$ - 5 unavailable & 74 (50.3\%) - 3 unavailable \\
\hline Diabetes & $47(28.8 \%)$ - 1 unavailable & $49(33.3 \%)$ - 3 unavailable \\
\hline Anticoagulation & 3 unavailable & 2 unavailable \\
\hline Nil & $93(57.8 \%)$ & $76(51.4 \%)$ \\
\hline Warfarin & $3(1.9 \%)$ & $1(0.7 \%)$ \\
\hline Aspirin & $25(15.5 \%)$ & $18(12.2 \%)$ \\
\hline Clopidogrel & $5(3.1 \%)$ & $3(2 \%)$ \\
\hline Treatment dose heparin & $3(1.9 \%)$ & $4(2.7 \%)$ \\
\hline Prophylactic dose low molecular weight heparin & $19(11.8 \%)$ & $23(15.5 \%)$ \\
\hline Multiple & $13(8.1 \%)$ & $23(15.5 \%)$ \\
\hline INR & 1 unavailable & 2 unavailable \\
\hline$<1.5$ & $160(98.1 \%)$ & 144 (97.3\%) \\
\hline$>1.5$ & $3(1.9 \%)$ & $4(2.7 \%)$ \\
\hline Platelets $\left(10^{9} / \mathrm{L}\right)$ & 1 unavailable & 3 unavailable \\
\hline$<50$ & $1(0.6 \%)$ & $1(0.7 \%)$ \\
\hline$>50,<100$ & $4(2.5 \%)$ & $4(2.7 \%)$ \\
\hline$>100$ & 158 (96.9\%) & $142(96.6 \%)$ \\
\hline
\end{tabular}

with those performed under image guidance (19/269 patients $=7.1 \%)(p=0.219$, Table 2$)$.

\section{Access-site complications}

There were 20 complications in total (Table 3). The total number of patients having either 4-Fr or 6-Fr sheaths was 334, of which 320 were for femoral arterial access. The overall post procedure complication rates were significantly greater following catheterisation with 6-Fr sheaths $(17 / 152(11.2 \%))$ versus $4-\mathrm{Fr}$ systems (3/168 $(1.8 \%))(p=0.0007)$ (Fig. 1). Compared with 4-Fr arterial catheterisation, the odds ratio (OR) for complication when using a 6-Fr system was 6.9 (95\% CI 2.0-24.0). Of the 17 complications in the 6-Fr group; 1 haematoma required surgical management, 1 case of distal embolization required further endovascular management by Interventional Radiology and 1 case of distal embolization was managed medically. The remaining were self-limiting haematomas.

There were 3 complications in the 4-Fr group consisting of 1 self-limiting haematoma, 1 pseudoaneurysm formation, and 1 haematoma requiring surgical management. There was no significant difference between $4-\mathrm{Fr}$ vs $6-\mathrm{Fr}$ systems for major complications (defined as those delaying discharge or requiring escalation of treatment).
Overall in both groups (4Fr and 6Fr), antegrade punctures $(9 / 78=11.5 \%)$ were associated with significantly greater complication rates than retrograde punctures $((11 / 242=4.6 \%) \quad(p=0.027)$ (Fig. 2$)$. Compared with the retrograde approach, the odds ratio for complication following antegrade puncture was 2.74 (95\% CI 1.09-6.88). Considering $6 \mathrm{Fr}$ catheterisation alone, complications were seen following $7 / 28$ (25\%) antegrade procedures and 10/ 124 (8.1\%) retrograde procedures, comprising a significantly elevated risk for the former $(p=0.018)$. The OR for complication following a $6 \mathrm{Fr}$ antegrade procedure, compared with retrograde, was 3.8 (95\% CI 1.3 to 11).

Only $0.9 \%$ of patients with complications required surgical intervention post procedure to correct access site complications. However; a comparison of complication rates between the remaining patient and procedure related parameters, including the seniority of the operator and the number of arterial passes, did not reach statistical significance.

In terms of anticoagulation, although 13/164 (7.9\%) of patients receiving intra-procedural heparin developed complications, compared with 5/150 (3.3\%) for those receiving no anticoagulation during the procedure, the difference between these two group did not reach significance $(p=0.093$, Table 2$)$. In addition, none of the 16 patients with pre-procedural INR $>1.5$ or platelets $<100$ 
Table 2 Arterial access characteristics/technique

\begin{tabular}{|c|c|c|c|c|}
\hline & \multirow{2}{*}{$\begin{array}{l}\text { 4-French } \\
\text { (168 procedures) }\end{array}$} & \multirow{2}{*}{$\begin{array}{l}\text { 6-French } \\
\text { (152 procedures) }\end{array}$} & \multicolumn{2}{|c|}{ Access Site Characteristic for BOTH 4Fr and 6Fr procedures } \\
\hline & & & $\begin{array}{l}\text { Difference in complication rates } \\
\text { ( } \mathrm{x}=\text { complication) }\end{array}$ & $p$-value \\
\hline \multicolumn{5}{|l|}{ Patient side of puncture } \\
\hline Left & 72 & 69 & \multirow{3}{*}{$\begin{array}{l}\text { Left }(n=141, C x \text { in } 5.7 \%) \text { vs right groin } \\
(n=178, C x \text { in } 6.7 \%)\end{array}$} & \multirow[t]{3}{*}{$p=0.696$} \\
\hline Right & 95 & 83 & & \\
\hline Unrecorded & 1 & & & \\
\hline \multicolumn{5}{|l|}{ Seniority of operator } \\
\hline Junior radiology trainee & 16 & 16 & \multirow{4}{*}{$\begin{array}{l}\text { Junior }(n=32, C x \text { in } 0.0 \%) \text { vs senior operator } \\
(n=287, C x \text { in } 7.0 \%) \text { (fellow or consultant) }\end{array}$} & \multirow[t]{4}{*}{$p=0.240$} \\
\hline Interventional radiology fellow & 132 & 116 & & \\
\hline Consultant & 20 & 19 & & \\
\hline Unrecorded & 0 & 1 & & \\
\hline \multicolumn{5}{|l|}{ Direction of puncture } \\
\hline Retrograde & 118 & 124 & \multirow{2}{*}{$\begin{array}{l}\text { Retrograde }(n=242, C x \text { in } 4.6 \%) \text { vs antegrade } \\
(n=78, C x \text { in } 11.5 \%) \text { puncture }\end{array}$} & \multirow[t]{2}{*}{$p=0.027$} \\
\hline Antegrade & 50 & 28 & & \\
\hline \multicolumn{5}{|l|}{ Artery punctured } \\
\hline External Iliac Artery & 1 & 1 & & \\
\hline CFA & 161 & 144 & \multirow{2}{*}{$\begin{array}{l}\text { CFA }(n=305, C x \text { in } 6.2 \%) \text { vs SFA } \\
(n=13, \text { Cx in } 7.1 \%)\end{array}$} & \multirow[t]{2}{*}{$p=0.604$} \\
\hline SFA & 6 & 7 & & \\
\hline \multicolumn{5}{|l|}{ Number of passes } \\
\hline 1 & 142 & 130 & \multirow{2}{*}{$\begin{array}{l}\text { Single }(n=272, C x \text { in } 5.5 \%) \text { vs multiple } \\
(n=48, C x \text { in } 10.4 \%) \text { passes }\end{array}$} & \multirow[t]{2}{*}{$p=0.200$} \\
\hline$>1$ & 26 & 22 & & \\
\hline Vessel calcification: Nil & $43: 125$ & $72: 80$ & $\begin{array}{l}\text { Calcified }(n=115, C x \text { in } 8.7 \%) \text { vs non-calcified } \\
(n=205, C x \text { in } 4.9 \%)\end{array}$ & $p=0.176$ \\
\hline Scarred groin: Nil & $14: 154$ & $39: 113$ & $\begin{array}{l}\text { Scarred }(n=53, C x \text { in } 5.7 \%) \text { vs non scarred } \\
(n=267, C x \text { in } 6.4 \%)\end{array}$ & $p>0.999$ \\
\hline \multicolumn{5}{|l|}{ Habitus } \\
\hline Raised BMI: normal/low & $57: 111$ & $37: 114$ & $\begin{array}{l}\text { Raised }(n=94, C x \text { in } 5.3 \%) \text { vs normal BMl } \\
(n=225, C x \text { in } 6.7 \%)\end{array}$ & $p=0.651$ \\
\hline Unrecorded & & 1 & & \\
\hline \multicolumn{5}{|l|}{ Puncture technique } \\
\hline Manual palpation & 45 & 6 & \multirow{4}{*}{$\begin{array}{l}\text { Manual palpation }(n=51, C x \text { in } 2.0 \%) \text { vs image } \\
\text { guided }(n=269, C x \text { in } 7.1 \%)\end{array}$} & \multirow[t]{4}{*}{$p=0.219$} \\
\hline Fluoroscopic guidance & 9 & 7 & & \\
\hline Ultrasound & 62 & 81 & & \\
\hline Combination & 52 & 58 & & \\
\hline Anticoagulation during procedure & 2 unavailable & 4 unavailable & & \\
\hline Nil & 104 & 46 & \multirow{2}{*}{$\begin{array}{l}\text { Anticoagulation }(n=164, C x \text { in } 7.9 \%) \text { vs none } \\
(n=150, C x \text { in } 3.3 \%)\end{array}$} & \multirow[t]{2}{*}{$p=0.093$} \\
\hline Intra-arterial heparin (3-5000 Units) & 62 & 102 & & \\
\hline \multicolumn{5}{|l|}{ Closure method } \\
\hline Manual compression & 163 & 87 & \multirow{7}{*}{$\begin{array}{l}\text { Manual compression ( } n=250, C x \text { in } 6.4 \%) \text { vs } \\
\text { closure / compression device }(n=68, C x \text { in } 5.8 \%)\end{array}$} & $p=>0.999$ \\
\hline Angioseal & 4 & 54 & & \\
\hline Exoseal & 1 & 5 & & \\
\hline Additional femstop & 0 & 3 & & \\
\hline Other (unrecorded) vascular closure device & 0 & 1 & & \\
\hline Vascular sheath left in-situ & 0 & 1 & & \\
\hline Unrecorded & & 1 & & \\
\hline
\end{tabular}


Table 3 Summary of complications between 4-Fr vs 6-Fr systems

\begin{tabular}{llllll}
\hline & 4 French & & & 6 French & Further active management \\
\cline { 2 - 3 } & Self-limiting & Further active management & & Self-limiting & 1 antegrade (surgery) \\
Complication & 1 antegrade & 1 antegrade (surgery) & & 14 (8 retrograde, 6 antegrade) & 1 retrograde (medical) \\
Pseudoaneurysm & - & 1 retrograde & & 1 retrograde (endovascular by IR) \\
Distal embolism & - & - & &
\end{tabular}

developed complications. These data were well recorded. Specifically looking at complications in patients receiving anticoagulation prior to the procedure (warfarin, aspirin, clopidogrel, treatment dose heparin and prophylactic dose heparin), although there was a higher number of complications in the anticoagulation group compared with the 'no anticoagulation' group, no statistical difference was demonstrated $(p=0.115)$; $12 / 144$ ( $8.3 \%)$ of those receiving prior anticoagulation developed complications, compared with $7 / 171$ (4.1\%), for those that had not (OR 2.13; 95\% CI 0.816 to 5.562 ).

\section{Discussion}

Access site bleeding complications have been reported in up to $19.3 \%$ of patients following femoral arterial catheterisation (Cantor et al., 2007), with major femoral bleeding associated with adverse outcomes, including prolonged hospital stay, increased blood transfusion requirements and decreased long-term survival (Doyle et al., 2008).

With the advent of low-profile devices, smaller sheaths have been introduced and intuitively, due to their smaller size, 4-Fr vascular access sheaths are expected to reduce the risk of post-procedural complications. The use of $4 \mathrm{Fr}$ access sheaths is associated with some technical difficulties such as a reduction in the ability to perform angiography via the sheath with a 4-Fr catheter in situ and increased difficulty with advancing some catheters within the sheath due to less physical space within the sheath. However, these difficulties are offset if there is reduction in complications. In a randomised study of patients undergoing diagnostic coronary angiography via the femoral arterial approach, 91 patients receiving 4-Fr arterial catheterisation were compared with 86 for whom 6-Fr catheters were used (Cantor et al., 2007). Complications were recorded in $22 \%$ of patients treated with 6 - $\mathrm{Fr}$ catheters compared to $10 \%$ in those with 4-Fr catheters $(p=0.11)$; the majority of these complications were minor. Our results demonstrate a similar trend. Our data are also comparable to that of Durst et al. (Durst et al., 2007), confirming reduced rates of overall complications following femoral arterial access with 4-Fr compared to 6 - Fr systems of $1.8 \%$ and $11.2 \%$, respectively. With either system, however, the majority of complications were minor and the overall number of immediate access site related complications is low, with an even smaller number of major complications.

Previously reported independent risk factors for haemorrhagic complications following femoral arterial catheterisation include increased patient age, increasing sheath size, anticoagulation and raised body mass index (BMI) (Doyle et al., 2008; Wheatley et al., 2011). Our data confirm a higher complication risk with increasing sheath size (6-Fr compared with 4-Fr systems). In addition, we have demonstrated a higher rate of minor complications,

\section{Complications following arterial catheterisation with $6-F r$ versus 4 -French sheaths}

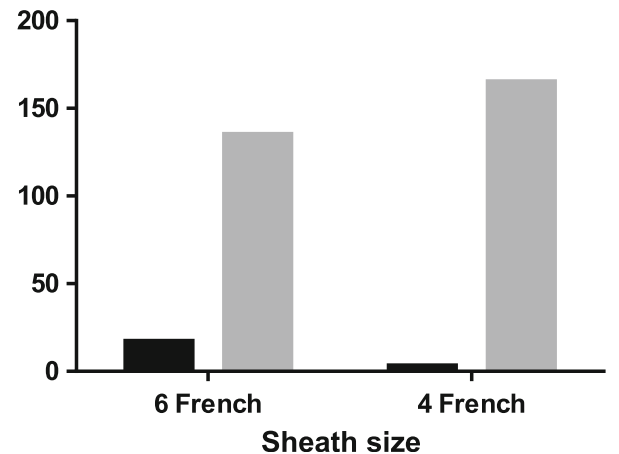

Complication

No complication

Sheath size

Fig. 1 Bar-chart demonstrating lower complication rates following 4-Fr arterial catheterisation compared with 6-Fr systems. Legend: Complications following arterial catheterisation with 6-Fr versus 4- Fr sheaths 


\section{Complications following arterial catheterisation with ante- versus retrograde punctures}
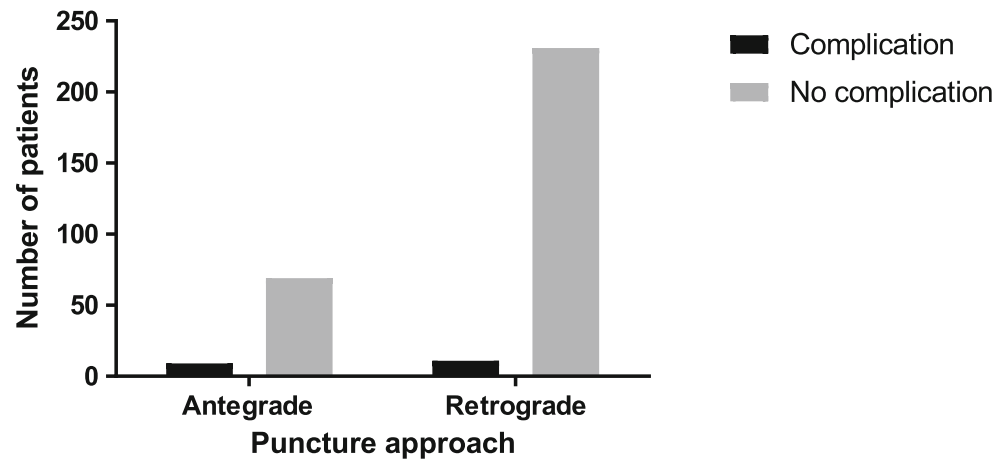

Legend: Complications following arterial catheterisation with ante-versus retrograde punctures

when using an antegrade approach compared with a retrograde approach. Reasons for this may include difficulty in obtaining adequate manual compression in patients with high BMI, high skin entry sites for antegrade punctures, as well as initial guidewire entry into the profunda rather than superficial femoral artery resulting in prolonged manipulation and increase of minor groin hematoma as a consequence. Recent reports describe no added morbidity in planned antegrade superficial femoral arterial (SFA) punctures versus CFA punctures (Kweon et al., 2012). A further retrospective study comparing complications in antegrade punctures of the CFA $(n=50)$ vs SFA punctures $(n=130)$ using vascular closure systems similarly reported an overall low access site complication rate of $8.9 \%$, with no significant difference between CFA and SFA access, or dependence on sheath size (Gutzeit et al., 2012).

No significant increase in complication rate was demonstrated in patients receiving anticoagulation prior to the procedure.

\section{Limitations}

Despite the data being collated prospectively, the patients were not randomised. Furthermore, choice of vascular sheath size was reliant on the choice of the principal operator and therefore results may reflect an additional selection bias. Patients switching from 4-Fr to 6-Fr systems were also not recorded as a separate cohort, a subgroup of patients that were potentially liable to an increased complication risk from changing vascular access sheaths during a procedure. The number of major complications is low and for this subgroup of complications, a significant difference between the two catheterisation systems is not confirmed. A study involving a much larger number of patients would be required to conclusively state that there are no significant differences in major complication rates between 4-Fr and 6-Fr systems.

\section{Conclusion}

Although our study has confirmed a significant reduction in overall complications when using a 4-Fr vascular sheath rather than a 6-Fr sheath in transfemoral arterial access for vascular interventional procedures, the majority of complications are minor, with no need for further intervention. The only additional factor demonstrating significance in complications was antegrade puncture. No significant difference has been demonstrated between the use of either sheath systems for major complications. Given the practical limitations of using a smaller system, these and earlier results do not justify the routine use of 4-Fr sheath systems as the primary sheath size for all endovascular procedures. As with all aspects of endovascular intervention, the choice of sheath size must be dictated by patient characteristics and the specific procedure planned, in order to balance safety, successful outcome and treatment economy.

\section{Abbrevations \\ BMI: Body mass index; CFA: Common femoral arterial; Cx: Complication; Fr: French; IR: Interventional Radiology; OR: Odds ratio; SFA: Superficial femoral arterial; SIR: Society of Interventional Radiology}

Availability of data and materials

Yes. Please contact author for data requests.

\section{Authors' contributions}

Guarantor of integrity of the entire study: RC, LR. Study concepts and design: LR, AMB, RM. Literature research: RC, AW, LR. Clinical studies: RC, AW, LR. Experimental studies/data analysis: N/A. Statistical analysis: AW, RC, LR. Manuscript preparation: RC, AW, RM, AMB, LR. Manuscript editing: RC, AW, $\mathrm{RM}, \mathrm{AMB}, \mathrm{LR}$. All authors read and approved the final manuscript.

\section{Authors' information}

Raymond CHUNG; rchung@doctors.org.uk, Consultant Radiologist, Department of Diagnostic Radiology, Khoo Teck Puat Hospital, Singapore. Alex WELLER; alweller@gmail.com, Consultant Radiologist, Radiology Department, Northwick Park Hospital, UK.

Robert MORGAN; Robert.Morgan@stgeorges.nhs.uk, Consultant Radiologist, Radiology Department, St. George's University Hospitals NHS Foundation Trust, UK. 
Anna-Maria BELLI; Anna.Belli@stgeorges.nhs.uk, Professor of Interventional Radiology \& Consultant Radiologist, Radiology Department, St. George's University Hospitals NHS Foundation Trust, UK. Lakshmi RATNAM; Lakshmi.Ratnam@stgeorges.nhs.uk, Consultant Radiologist, Radiology Department, St. George's University Hospitals NHS Foundation Trust, UK

\section{Ethical approval and consent to participate}

St. George's Joint Research and Enterprise Office (St. George's Healthcare NHS Trust, London) reviewed the protocol against the requirements of the Research Governance Framework for Health and Social Care 2005, incorporating the Medicines for Human Use (Clinical Trials) Regulations 2004. They can confirm that this study does not require ethical review.

\section{Consent for publication}

Not applicable.

\section{Competing interests}

The authors declare that they have no competing interests.

\section{Publisher's Note}

Springer Nature remains neutral with regard to jurisdictional claims in published maps and institutional affiliations.

\section{Author details}

'Diagnostic Radiology, Khoo Teck Puat Hospital, 90, Yishun Central 768828, Singapore. ${ }^{2}$ Radiology, Northwick Park Hospital, Watford Road, Harrow HA1 3UJ, UK. ${ }^{3}$ Radiology, St. George's University Hospitals NHS Foundation Trust, Blackshaw Road, London SW17 OQT, UK.

Received: 1 February 2018 Accepted: 5 July 2018

Published online: 23 August 2018

\section{References}

Baumann F, Yates T, Gandhi R, Benenati J, Pena C, Katzen BT (2015) Single-center experience comparing the application of small-caliber versus large-caliber arterial access closure in a consecutive series of patients. J Vasc Interv Radiol 26(9):1285-1289

Cantor WJ, Mahaffey KW, Huang Z, Das P, Gulba DC, Glezer S et al (2007) Bleeding complications in patients with acute coronary syndrome undergoing early invasive management can be reduced with radial access, smaller sheath sizes, and timely sheath removal. Catheter Cardiovasc Interv 69(1):73-83

Das R, Ahmed K, Athanasiou T, Morgan RA, Belli AM (2011) Arterial closure devices versus manual compression for femoral haemostasis in interventional radiological procedures: a systematic review and meta-analysis. Cardiovasc Intervent Radiol 34(4):723-738

Doyle BJ, Ting HH, Bell MR, Lennon RJ, Mathew V, Singh M et al (2008) Major femoral bleeding complications after percutaneous coronary intervention: incidence, predictors, and impact on long-term survival among 17,901 patients treated at the Mayo Clinic from 1994 to 2005. JACC Cardiovasc Interv 1(2):202-209

Durst R, Lotan C, Nassar H, Gotsman M, Mor E, Varshitzki B et al (2007) Comparison of 4 and 6 French catheters for coronary angiography: realworld modeling. Isr Med Assoc J 9(4):290-293

Fairley SL, Lucking AJ, McEntegart M, Shaukat A, Smith D, Chase A et al (2016) Routine Use of Fluoroscopic-Guided Femoral Arterial Puncture to Minimise Vascular Complication Rates in CTO Intervention: Multi-centre UK experience. Heart Lung Circ 25(12):1203-1209

Gutzeit A, van Schie B, Schoch E, Hergan K, Graf N, Binkert CA (2012) Feasibility and safety of vascular closure devices in an antegrade approach to either the common femoral artery or the superficial femoral artery. Cardiovasc Intervent Radiol 35(5):1036-1040

Honda T, Fujimoto K, Miyao Y, Koga H, Hirata Y (2012) Access site-related complications after transradial catheterization can be reduced with smaller sheath size and statins. Cardiovasc Interv Ther 27(3):174-180

Kweon M, Bhamidipaty V, Holden A, Hill AA (2012) Antegrade superficial femoral artery versus common femoral artery punctures for infrainguinal occlusive disease. J Vasc Interv Radiol 23(9):1160-1164

Omary RA, Bettmann MA, Cardella JF, Bakal CW, Schwartzberg MS, Sacks D et al (2003) Quality improvement guidelines for the reporting and archiving of interventional radiology procedures. J Vasc Interv Radiol 14(9 Pt 2):S293-S295

Rajebi H, Rajebi MR (2015) Optimizing common femoral artery access. Tech Vasc Interv Radiol 18(2):76-81
Tzinieris IN, Papaioannou Gl, Dragomanovits SI, Deliargyris EN (2007) Minimizing femoral access complications in patients undergoing percutaneous coronary interventions: a proposed strategy of bony landmark guided femoral access, routine access site angiography and appropriate use of closure devices. Hell J Cardiol 48(3):127-133

Wagner J, Gandhi RT, Powell A (2015) Technical approach to Antegrade femoral access. Tech Vasc Interv Radiol 18(2):82-86

Wheatley BJ, Mansour MA, Grossman PM, Munir K, Cali RF, Gorsuch JM et al (2011) Complication rates for percutaneous lower extremity arterial antegrade access. Arch Surg 146(4):432-435

\section{Submit your manuscript to a SpringerOpen ${ }^{\odot}$ journal and benefit from:}

- Convenient online submission

- Rigorous peer review

- Open access: articles freely available online

- High visibility within the field

- Retaining the copyright to your article

Submit your next manuscript at $\boldsymbol{\nabla}$ springeropen.com 